\title{
Historias de familia: memoria, feminidad y afectos
}

María Moreno*

\begin{abstract}
RESUMEN
LAS MUJERES HAN INCURSIONADO EN FORMAS DE ESCRIBIR SOBRE EL PASADO QUE EXPLORAN ÁREAS TANGENCIALES A LA MAYOR PARTE DE ESCRITOS QUE ABORDAN EN ESPECIAL EL CAMBIO ECONÓMICO Y POLítico. SUS FORMAS DE ESCRITURA SON VISTAS COMO MARGINALES, IMPURAS, Y APARENTEMENTE TRIVIALES. Sin EMBARGO, OFRECEN MANERAS DE VER EL PASAdo QUe Ligan lo PERSONAL CON LO POLÍtico. EN ESTE TRABAJO EXPLORO LAS MEMORIAS FAMILIARES DE MUJERES de tres generaciones de dos familias Quiteñas de Clase media. Siendo yo misma parte de una de las familias, AQUí REALIZO NO SOLAMENTE UN ANÁLISIS, SINO UNA CO-CONSTRUCCIÓN DE HISTORIAS FAMILIARES, EN DIÁLOGO CON MUJERES de DIFERENTES GeNERACIONES. A TRAVÉS DEL ACERCAMIENTO A CIERTOS OBJETOS GUARDADOS O PRODUCIDOS POR MIEMBROS DE LA FAMILIA, ANALIZO EL TRABAJO DE MEMORIA EN LAS HISTORIAS FAMILIARES NARRADAS Y REVIVIDAS POR ESTAS MUJERES, CON UN ENFOQUE QUE PERSIGUE SOBRE TODO DAR CUENTA DE LAS NEGOCIACIONES CON LAS NOCIONES DE FEMINIDAD Y CON LA IDEOLOGÍA DEL ORGULLO POR EL TRABAJO.
\end{abstract}

Palabras Clave: memorias familiares - Feminidad - Familias Quiteñas.

Family Stories: Memory, Femininity and Affections

\begin{abstract}
WOMEN HAVE VENTURED INTO WAYS OF WRITING ABOUT THE PAST THAT EXPLORE AREAS TANGENTIAL TO THE MAJORITY OF WRITINGS THAT ESPECIALLY ADDRESS ECONOMIC AND POLITICAL CHANGE. THEIR FORMS OF WRITING

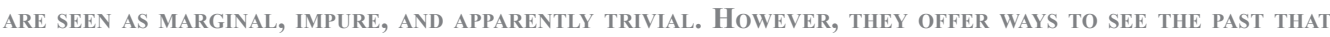
LINK THE PERSONAL WITH THE POLITICAL. IN THIS WORK, I EXPLORE FAMILY MEMORIES FROM THREE GENERATIONS OF WOMEN FROM TWO MIDDLE CLASS QUITEÑ FAMILIES. BEING MYSELF PART OF ONE OF THESE FAMILIES, I OFFER NOT ONLY AN ANALYSIS, BUT ALSO A CO-CONSTRUCTION OF FAMILY STORIES IN DIALOGUE WITH WOMEN OF DIFFERENT generations. Through engagement with Certain ObJects STORED OR Produced by famiLy Members, I ANALYZE THE WORK OF REMEMBERANCE IN THE FAMILY STORIES NARRATED AND REVIVED BY THESE WOMEN WITH AN APPROACH THAT SEEKS ABOVE ALL TO ACCOUNT FOR NEGOTIATIONS WITH NOTIONS OF FEMININITY AND WITH THE IDEOLOGY OF PRIDE IN WORK.
\end{abstract}

KEYWORDS: FAMILY MEMORIES - FEMININITY - QUITEÑO FAMILIES.

* María Moreno Parra, Ph.D. en Antropología por la Universidad de Kentucky. Ha investigado temas de etnicidad y género en el activismo indígena; belleza, raza y nación, y activismo antirracista. Recientemente fue investigadora postdoctoral del proyecto Anti-Racismo Latinoamericano en una Era "Post-Racial, LAPORA". Se desempeña actualmente como profesora invitada del Departamento de Sociología y Género en Flacso, Ecuador. Correo electrónico: msmorenop@hotmail.com. 


\section{Memoria, familia, feminidad}

$\mathrm{E}^{\mathrm{n}}$ n el mundo moderno existe una tendencia a personalizar la memoria. "Parece ser que al declinar las formas colectivas de memoria una carga cada vez mayor se pone en el individuo" (Gillis, 1994: 15). Es más, el énfasis en guardar, conservar y recordar ha sido una tarea cuya responsabilidad ha recaído en mujeres. Ellas se han convertido en archivistas, historiadoras y guardianas de la memoria familiar.

Las mujeres administran estos conjuntos de fragmentos de distinto orden que animan la construcción de las memorias familiares: objetos que pertenecieron a antepasados, álbumes familiares, recetas de la familia, recuerdos de viajes, de bautizos, primeras comuniones y matrimonios. Sin embargo, todo esto no constituye de por sí la memoria familiar, hasta que no se realice su interpretación, esto es, hasta que efectuamos el trabajo de la memoria, consistente en darles algún significado.

Producimos el significado de estos artefactos de memoria colocándolos dentro de sistemas de representación y realizando prácticas de producción de significado (Hall, 2000: 28). Las familias suelen contar las historias y anécdotas familiares, las cuales interactúan y se influyen mutuamente con los artefactos de memoria. Quiero centrar este trabajo en las historias familiares contadas por las mujeres de dos familias y en los trabajos de memoria en los que se encuentran comprometidas tres generaciones: abuelas, madres y nietas -siendo yo miembro de la última generación en una de las familias en mención en este trabajo ${ }^{1}$ -

En el caso de una de las familias, el trabajo de memoria tiene como pretexto un libro de cocina que reúne recetas familiares. En la otra familia, el trabajo de memoria se realiza en torno a bisabuelos y escritos dejados por ellos. Parto de la idea de que existen cambios y continuidades en la transmisión de la memoria y que estos se relacionan con el género (Piscitelli, 1996). En ambas familias, el trabajo de la memoria se produce matrilinealmente: de la abuela materna a la nieta. En los dos casos, la tercera generación muestra interés en conocer y registrar las memorias familiares - mediado este proceso por el trabajo de memoria de la segunda- y siente mayor identificación con el lado matrilineal de la familia. Existen algunas similitudes en ambos casos que me han hecho reflexionar sobre las diferencias de género en la transmisión de memorias familiares. No obstante, también existen diferencias, pues los significados de cada historia familiar están leídos desde necesidades específicas a las distintas generaciones.

Este análisis está basado en entrevistas, conversaciones y discusiones sobre objetos de memoria familiar de tres generaciones de mujeres de dos familias mestizas quiteñas de clase media. En estas conversaciones, recapitulé junto con otras mujeres historias que se cuentan en cada familia, al tiempo que aprendí más junto a ellas sobre otras historias que no habíamos conocido de las abuelas y bisabuelas. En este trabajo estoy implicada no solo como miembro de una de las familias, sino que participo "en el acto de representar las necesidades, metas, situaciones de los otros, y en efecto quiénes son" (Alcoff, 1991: 9²). Más aún, este trabajo de memoria familiar no es simplemente una recopilación de información. Claramente, al "recopilar" estas memorias, me encontré co-construyéndolas junto a las mujeres de estas familias: hablando de las mismas historias, si bien con nuevos detalles o revelaciones de elementos que no conocíamos, y de esa forma abriendo la posibilidad de reinterpretaciones. La posicionalidad de la persona que investiga siempre es relevante al contenido de la escritura y en contextos que implican formas de

1 Dejaré de lado los otros múltiples objetos que conforman las memorias familiares: álbumes de fotos, objetos pasados de una generación a otra, cartas, tarjetas, regalos, muebles, joyas, vitrinas, etc., que conforman la memoria archivista y artefactual de las familias desde la modernidad.

2 Las traducciones de las citas de las referencias en inglés son de mi autoría. 
auto-etnografía, la propia investigadora está imbricada en delicadas redes de afecto ${ }^{3}$. En efecto, esta es una representación parcial, que se enfoca en la agencia de estas mujeres y ofrece "una forma de ser en el mundo" (Ibíd.: 21):

“...porque nos importa lo que se dice de nosotros, quién lo dice y para quién se dice: tener la oportunidad de hablar sobre la propia vida, dar cuenta de ella, interpretarla, es esencial para dirigir esa vida, en lugar de ser dirigida durante ella" (Lugones y Spelman, 1986: 22).

Empezaré refiriéndome a los objetos de los que ha partido el análisis de estas historias familiares y del trabajo de memoria que han generado en cada caso. Luego pasaré a dar una respuesta a cuál podría ser el significado de estas historias y cómo se producen continuidades y rupturas en las interpretaciones de las distintas generaciones.

\section{La farmacéutica y el bibliotecario de González Suárez}

El ingreso a la casa de mis abuelos maternos está presidido por una foto del rostro de la bisabuela (también del lado materno). Tiene una mirada severa y una postura compuesta y aplomada. Esta foto hace sentido con mucho de lo que hemos oído contar sobre ella. Una mujer férrea, una boticaria que trabajó toda la vida. Para mí fue, por mucho tiempo, la única de la generación de los bisabuelos de la que tenía una imagen clara. Los otros antepasados de esa generación, a excepción de su esposo, mi bisabuelo, están borrados de mis memorias familiares. ¿Por qué y cómo ha llegado hasta mí este conocimiento y no el de las otras tres parejas de bisabuelos, en torno a las cuales podría haber reconstruido los recuerdos familiares? En buena parte, por lo que se cuenta por vía materna.

De uno de sus cajones en los que están las fotos de la familia y varios recuerdos, mi madre extrajo un cuaderno escrito por mi bisabuelo, José Manuel, y una libreta con las recetas de belleza de mi bisabuela Luz María ${ }^{4}$. El cuaderno de mi bisabuelo empieza así:

\section{Episodios públicos y privados de la vida del Ilustrísimo y Reverendo Sr. Dr. Federico González} Suárez, Dignísimo Arzobispo de Quito. Desde el año de 1895 hasta el de 1917 en que murió.

Conocí más sobre la vida de mi bisabuelo en la medida en que narra estos episodios de la vida de un personaje de la historia del Ecuador. Se dice que los hombres tienden a relatar episodios públicos, épicos, llenos de acción valiente y emoción (Piscitelli, 1996: 90). Esto se puede apreciar a través de las anécdotas que suele contar el bisabuelo José Manuel. Por ejemplo, relata las confrontaciones entre liberales y conservadores, como cuando Ibarra se salvó de un saqueo, premio que había sido prometido por el bando liberal a Escandón, un liberal colombiano. González Suárez negoció que no se realice el saqueo a cambio de 500 sucres, cuando en un principio le habían pedido 2000.

Conocí más sobre la vida de mi bisabuelo en la medida en que narra estos episodios de la vida de un personaje de la historia del Ecuador. Se dice que los hombres tienden a relatar episodios públicos, épicos, llenos de acción valiente y emoción (Piscitelli, 1996: 90). Esto se

3 He omitido de este análisis dolorosas experiencias relacionadas al patriarcado y la desigualdad de género, que cabrían en un escrito con objetivos diferentes. Este "olvido" consciente tiene como objeto no representarnos como víctimas, pues el trabajo de la memoria, después de todo, también sirve para curar heridas del pasado. Confronto el problema que plantean Lugones y Spelman (1986: 31) relativo a "teorizar de una manera respetuosa" cuando se preguntan si nuestras preocupaciones de rendir cuentas "a la profesión" entran en contradicción con las preocupaciones sobre rendir cuentas a aquellos sobre los que teorizamos. Por ello, he realizado una selección del material para enfatizar las negociaciones con las ideologías sobre la familia así como las ideas normativas de feminidad y las acomodaciones o confrontaciones que frente a estas realizan las mujeres de las familias analizadas. También hago referencia a elementos de clase e indirectamente raza (no nombrada).

4 Los nombres de los participantes en esta investigación fueron cambiados por seudónimos cuando así lo decidieron los involucrados. 
puede apreciar a través de las anécdotas que suele contar el bisabuelo José Manuel. Por ejemplo, relata las confrontaciones entre liberales y conservadores, como cuando Ibarra se salvó de un saqueo, premio que había sido prometido por el bando liberal a Escandón, un liberal colombiano. González Suárez negoció que no se realice el saqueo a cambio de 500 sucres, cuando en un principio le habían pedido 2000.

El episodio más épico corresponde a aquel con el cual termina el cuaderno de memorias del bisabuelo_-el arrastre de Eloy Alfaro:

“... a las tres o cuatro semanas se cumplía lo que predijo Monseñor, "Ha llegado la hora de Dios para el General Alfaro”!!! Después de ocho días presenciamos el arrastre del cadáver del General Alfaro en las calles de Quito y más, sin la cabeza, porque dicen que una comisión de las Logias, asi que salía el cadáver la puerta del ..., la arrancaron y se la llevaron, así llegó el gentio a la Plaza de la Independencia, yo lo vi, la gente lo levantaban al cadáver en el aire desnudito, iiQué horror!!... yo no puedo olvidarlo, el horror que me causó semejante acto!!!.. Yo estaba en la galería del Palacio Arzobispal que domina toda la calle del Banco Pichincha, en la esquina ese gentio se abrió y salió un cadáver que lo tiraban con unas sogas atadas a los pies, lo llevaron por la grada redonda de la Catedral, al pasar la grada lo alcancé a ver bien. El cadáver era el General Páez, sólo con los pantalones, de espaldas, asi lo llevaron hasta el cuartel de la Artillería que entonces era donde está hoy el Museo. Hasta tanto muy despacio avanzaba la gente hacia el Palacio Arzobispal, asi que llegaron a la esquina, se abrió ese gentio y asomó un cuerpo desnudo $y$ sin cabeza; todos decían -es el cuerpo del General Alfaro-; el tamaño lo atestiguaba, como era tan pequeño y la aglomeración tan apiñada que lo llevaban en el aire en brazos, así que lo vi, me produjo tal impresión que no pude seguir viéndolo, y me sali de la galería corriendo, pero cuando llegué a la puerta de la grada, tuve un susto tan brutal. Mi idea fue ir en busca de Monseñor para contarle todo, pero qué susto tan terrible que sufri al presentarme en la grada de la Curia, encontrarme con un gentío que habia invadido el cuarto de Monseñor; en dos trancos estuve delante de ellos, gritando "fuera, ¿qué quieren?"... En ese momento alcancé a oír la voz de Monseñor, que les decía, "afuera sinvergüenzas", entonces yo también grité fuera. La gente salió, asustada y desaparecieron".

El género de la persona influye en los temas, estructura, forma y estilos expresivos de las narrativas vitales (Siebert, 1996: 89). Los hombres suelen hablar más de hechos públicos: la vida política, el trabajo, la profesión. El bisabuelo decidió dejar para la posteridad esa parte de sus memorias, las relacionadas con su servicio a González Suárez. En la lectura que hice del texto estaba buscando otras cosas, las historias de familia, pero de ellas encontré un vacío. La historia relatada no corre paralela a su memoria familiar. En todo el texto sólo encontré una alusión a mi bisabuela, y está relacionada con episodios previos a la muerte de González Suárez:

"Tres días antes de su muerte me dijo "José, ¿dónde está Luz María?... Yo le dije, "adentro debe estar"; él me dijo, "llámala, anda a traerla"... Yo fui y regresé con mi Luz María y le dije, "Ilustrísimo Señor, aqui está mi Luzita". Ella le saludó con todo el respeto que le tenía. Entonces él me dijo "acerca una silla para que se siente”... así lo hice. Entonces Monseñor le dijo “iLuzita!... le he llamado para hacerle una súplica que es la siguiente, que me perdone porque yo me opuse a que fuera más pronto feliz, con su matrimonio con mi José!!...” Luzita se paró desesperada, llorando a gritos y diciéndole "Vuestra Señoría tiene que perdonarme por lo que con este motivo tuvo Vuestra Señoría tanto que sufrir".

No sabemos más por lo que escribe el bisabuelo la razón por la cual González Suárez pudo haber estado opuesto a este matrimonio. Sin embargo, mi abuela sí explica las razones de esta oposición: González Suárez temía perder a su bibliotecario y mano derecha si se casaba:

5 Conservo la manera en que está escrito el diminutivo de Luz por el abuelo, que utiliza "Luzita” en vez de Lucita. 


\begin{abstract}
"Mi papacito vivió y fue protegido y secretario de Monseñor González Suárez. Vivió con Monseñor desde la edad de los diez años. La abuelita le entregó a Monseñor, como antes sucedía que las familias les entregaban a los hijos a los conventos, le entregó a Monseñor a los diez años, y entonces Monseñor le educó, y todo lo que él sabía y era le debió a Monseñor, porque él puso todo su interés en educarle. Él era un bibliotecario número uno, sabía de las bibliotecas de Monseñor González Suárez y de sus papeles, hasta el último papelito"6.
\end{abstract}

La familia de la bisabuela también se había opuesto al matrimonio. Luzita, era hija de un liberal de cepa, Manuel Chiriboga Alvear, que había repartido monedas de oro en la inauguración del tren. La bisabuela fue "una de las primeras farmacéuticas graduadas por Alfaro". Los relatos sobre la bisabuela destacan que fue de las primeras mujeres profesionales y además una mujer que trabajó, lo cual difiere de las expectativas de género predominantes para la época. Luzita era el resultado de políticas liberales en cuanto a la educación de las mujeres, y seguramente Gónzalez Suárez resentía que este fruto del liberalismo hubiera seducido a su piadoso José7. Por su parte, la familia liberal tampoco consentía que la hija se casara con quien había sido criado por un cura.

Las formas de inscribir las memorias de las mujeres "han ofrecido maneras de ver el pasado que insisten en ligar lo personal con lo político, lo mundano con el magno evento, lo trivial con lo importante" (Holland, 1991: 9). Las historias de la familia pueden desdibujar las fronteras entre la reminiscencia personal, el compromiso cultural y la historia social. Eso pasa con esta memoria familiar, en la que se mezcla una historia de amor particular con las encarnizadas luchas políticas entre los bandos liberales y conservadores en las postrimerías del siglo XIX y los principios del XX.

Antes de continuar con las historias sobre la bisabuela, quisiera mencionar algo más sobre el cuaderno del bisabuelo. Si bien los temas y la estructura de su cuaderno se corresponden a campos sociales y culturales identificados como masculinos-eventos públicos, atributos masculinos de valentía, inteligencia, astucia (Piscitelli, 1996: 92) —, la manera en que relata los hechos dista mucho de corresponder al estilo identificado como predominantemente masculino: sintético, limitado en la expresión de sentimientos, y ligado a una lógica racional y política (Jelín, 2002: 107-8). En sus escritos, el bisabuelo hace muchas citas directas, escribe diálogos y utiliza el discurso reportado, antes que resumir y dar una idea general de la conversación (Leydersdorff et al., 1996: 3). El encanto de su cuaderno es el estilo vívido de su escritura mediante el cual queda claro su sentimiento de admiración por su protector, además del uso de formas de oralidad puesta por escrito.

Mi madre estuvo ligada emotivamente a este bisabuelo cariñoso y gran contador de historias. De su abuela le resuena todavía el "muchacha carishina", cuando no se sujetaba a su disciplina de hierro. En las memorias sobre los bisabuelos hay una especie de trastocamiento de roles. El bisabuelo centró los afectos de sus nietos, mientras las memorias de la abuela enfatizan otros aspectos normalmente asociados a hombres: la profesión y el trabajo. Mi abuela recuerda así a su madre:

\footnotetext{
"Mi madre fue una mujer profesional, fue como es pues, doctora en... la profesión de las boticarias... química! Fue graduada en farmacia y era especializada en cosas de belleza. Toda la vida trabajó mi madre en la profesión, hasta cuando cerca de morirse. Económicamente nosotros quedamos muy desvalijados cuando mis padres perdieron pues toda su fortuna y entonces ella se vio obligada
}

6 Historia de vida de mi abuela (Quito, agosto de 2004).

7 Cuando se casaron vivieron en el Palacio Arzobispal. La bisabuela conquistó a González Suárez con "las comidas que no había probado tiempo". También le había dicho que si es que Luzita le hubiera atendido desde antes -tanto con la comida, como con los cuidados derivados de su conocimiento de química farmacéutica- hubiera vivido más años. Los bisabuelos habían esperado la venia de González Suárez para poder casarse. Para sellar el perdón por no haberles dejado casar antes, González Suárez le había entregado a Luzita una de las medallas que alguna vez había recibido. Dice mi abuela: "Y Monseñor le quiso muchísimo y cuando se casó con mamacita, ellos vivieron los primeros tiempos en el Palacio Arzobispal y ahí nacieron mis primeros hermanos". 
a trabajar hasta bastante viejita, pese a que fisicamente era bastante bien tenida, pero yo me imagino que para mi, hacia un esfuerzo muy especial, porque quiso mucho a su familia, a sus hijos especialmente".

En la narrativa de mi abuela, existen varias referencias a la bisabuela, en las que se señala "la rebeldía femenina, las fuertes reacciones femeninas que parecen asociadas a la masculinidad" (Piscitelli, 1996: 97). La bisabuela renegó y renunció a su familia porque no aprobaron su matrimonio. En ello se muestra su valentía y su determinación:

\begin{abstract}
"Hubo ese problema en el hogar, que como papacito no fue bien recibido en la familia de mamacita, tuvieron que olvidarse de la familia, porque como te cuento antes se hacían tanto daño cuando no les agradaba el miembro de familia que ingresaba. Entonces la mamacita se olvidó de la familia, entonces nosotros casi no conocemos nuestros parientes quiteños, casi no sabemos quiénes son porque cuando se trataba de eso, mamacita decía que ella solamente es la esposa del papacito y nada más, que no tiene nadie más. Se había resentido tanto de tanta cosa que le hicieron al papacito que ella se olvidó de la familia. Entonces después, que ya había pasado bastante tiempo y nosotros ya éramos grandes, era que las mismas familias venian en pos de mamacita. "Luzita, dónde estás, por qué no te asomas Luzita, olvidate de las cosas que pasaron y vuelve”, y mamacita no volvió".
\end{abstract}

La bisabuela era una mujer de armas tomar. Para librarse de un compromiso matrimonial entró al convento y se hizo monja de la caridad. Le enviaron a Otavalo para que esté a cargo de la botica. Allí ayudaba "a preparar ungüentos y jarabes para combatir a los chinches que aquejaban a los indios de la zona" [sic]. Después, de la "misma forma que entró, salió" y se casó con mi bisabuelo.

\begin{abstract}
"Mi madre fue una mujer que tuvo su posición social, pero cuando vino la delegación militar esta chilena, entre los chilenos que habian venido, hubo un militar que le propuso matrimonio a mi madre y ella se comprometió a casar con él. Pero desgraciadamente mientras el tiempo de noviazgo, él no se portó bien y entonces mamá por deshacerse del compromiso, ella se entró en el convento y entonces ella fue hermana de la caridad, como era farmacéutica estuvo a cargo de ella la botica todo el tiempo, pero cuando en el convento le fue mal se salió y entonces se casó con mi padre”.
\end{abstract}

En los modelos de género predominantes se identifica la masculinidad con la dominación y la agresividad, mientras en la feminidad se produce una ambivalencia entre la superioridad espiritual de las mujeres y la sumisión y pasividad frente a los deseos de los hombres (Jelín, 2002: 100). Los episodios de la bisabuela tienen su propia carga épica. Describen una mujer rebelde, involucrada en asuntos románticos, al igual que las mujeres de la primera generación que analiza Piscitelli para el caso de familias terratenientes en Brasil (1996: 90), pero a diferencia de tales mujeres, los relatos familiares también enfatizan la trayectoria profesional y el trabajo de la bisabuela. De esa manera, estos relatos envían un mensaje a las nuevas generaciones: las identidades de género no tienen que seguir los estereotipos: en la familia hay mujeres, desde mucho atrás, que han salido del ámbito doméstico y que han integrado a sus vidas posibilidades que fueron predominantemente masculinas. Además, dichos relatos dan su lugar a las mujeres en uno de los mitos familiares: el orgullo del trabajo ${ }^{8}$, al que me referiré más adelante.

\title{
"Mamita Lucía: Recetas y Recuerdos"
}

Los libros de cocina constituyen fuentes utilizadas por historiadores para dar cuenta, entre otros temas, de historias culturales y de género. Las mujeres han utilizado la comida como un medio para hablar de sus experiencias, culturas y creencias. De esa forma, la comida permite vislumbrar vidas que podrían pasar desapercibidas - las vidas de mujeres comunes y corrientes.

8 Más adelante analizaremos uno de los "mitos familiares", el orgullo del trabajo, que se puede rastrear en las familias de clase media. 
Más aún, la alimentación y el cuidado define a las mujeres en formas que pueden limitar sus opciones, pero que también les otorgan un canal para crear lazos que unen (Counihan, 2012). Los autores de libros de cocina buscan crear comunidad, "tanto las reuniones inmediatas de la familia como las comunidades imaginadas de las naciones, los mercados y los movimientos sociales" (Pilcher, 2012: 43). En varias familias, las recetas de abuelas, madres u otros parientes suelen ocupar un lugar en la memoria familiar.

Hace poco tiempo, una de mis amigas más queridas, Camila, hizo un libro de cocina que se titula "Mamita Lucía: Recetas y Recuerdos". Mamita Lucía es su abuela. El libro comienza con once fotos que van de 1940 a 2003. Siete de estas fotos corresponden a Mamita Lucía en diferentes años en el período mencionado. En otras tres fotos aparece con "Papavo", su esposo. En una aparece con su esposo y sus cinco hijos cuando eran pequeños. El libro continúa con una sección denominada "¿Quiénes eran mis ancestros?” Allí constan referencias cortas y anecdóticas del padre, la madre, algunos abuelos y bisabuelos de la Mamita Lucía. Luego vienen una serie de memorias en una sección que se titula "Mis Primeros Recuerdos". En ella se relata la infancia de la mamita, luego el tiempo de internado y colegio, la vida con los abuelos maternos, el enamoramiento y matrimonio con Manuel, un tiempo en que vivieron en Cali, el episodio de los marcianos en Quito, y la primera casa. Allí concluye -y no concluye- el relato de las memorias de Mamita Lucía. En sus palabras:

"Esas fueron nuestras primeras aventuras por Ecuador y después por el mundo, pero todavía me faltan como cuarenta años de vida, los iré escribiendo poco a poco. Espero que hasta aqui se hayan divertido.

A propósito también quiero dejar recetas de cocina sencillas, para que hijos, nietas y bisnietos (y toda la generación del futuro) contenten con estas a sus amigos, maridos, novios o lo que sea. Dicen que con el tiempo el matrimonio va a desaparecer. ¿Será? Por eso disfruten de sus familias. Bueno ya mismo van las recetas".

A estas palabras le siguen unas caricaturas de la familia que están puestas en un árbol genealógico que va desde Mamita Lucía y Papavo, a los cinco hijos, a "los primos" (nietos) y los hijos de los primos. Continúa el texto con una entrevista a Mamita Lucía con preguntas parecidas a las de un "curioso" que trata de las preferencias de la Mamita Lucía en diversos temas. Una de las preguntas:

\footnotetext{
“¿Cuál fue su primer beso? Un beso a la velocidad. El único antes de mi marido. Yo bajaba al zaguán una noche, él ha estado en la puerta de entrada, no era una cita. Me quería sorprender. Yo bajo, él me abraza y besa y yo de la emoción me corro a mi cuarto. Nunca se repitió otro beso. Después conoci a Papavo que sacaba su carro y todos mis novios se quedaban en la esquina viendo, pobres guambras infelices. Manuel siempre tuvo su personalidad, era muy trabajador y aunque me parecía muy mayor, me casé con él".
}

Continúa con "Un consejo importante" de Mamita Lucía para su familia que termina con lo siguiente: "Ama como si no te hubieran herido, baila como si nadie te estuviera viendo y sonríe como si nunca hubieras llorado. Simplemente sé feliz".

Enseguida está el Diccionario de Mamita Lucía, con diferentes palabras como cipa, chulla, chuya, omoto, etc. y expresiones propias de ella. Sobre el agua de calahuala dice: "Ha sido buena para la artritis y como soy sorda, oi que era buena para la gastritis y desde ahí la tomo en ayunas. Me ha curado de ambas cosas. La recomiendo".

Finalmente, antes de las recetas, está transcrita una postal enviada por una de las hermanas de Mamita Lucía, en la que le hace un encargo. La postal cierra con una anécdota graciosa. Todo el texto está escrito en ese tono y enfatiza un estilo de relato muy propio de la familia: las historias de los parientes contadas para hacer reír (Como los casos señalados por Piscitelli, 1996: 90). 
La segunda parte del libro de cocina recoge las recetas propiamente: 55 recetas separadas por salsas, entradas, sopas, platos fuertes y postres. No todas estas recetas son de Mamita Lucía. Otros miembros de la familia también han contribuido con sus recetas: una de las hijas de Mamita Lucía, dos nietas, un nieto. También están parientes afines, como el esposo y la suegra de la nieta de Mamita Lucía.

En esta familia es muy importante la comensalidad. Se reúnen de cuando en cuando a comer cangrejos. Se recuerda a mujeres de la familia como Mamita Angélica (madre de Mamita Lucía) y a la propia Mamita Lucía porque siempre muestran su preocupación por la familia a través de la preparación de comida. Cuando Mamita Angélica visitaba a sus hijas siempre preparaba el postre. Cuando alguien de la familia cumple años, la Mamita Lucía ofrece hacer el pastel. Se reproduce y se mantiene así un mundo maternal, de los gustos primordiales y las comidas básicas (Bourdieu, en: Bardenstein, 2002: 375).

Podemos ver en textos como "Mamita Lucía: Recetas y Recuerdos" una relación entre la memoria y la comida, la identidad colectiva y la familiar, y la nostalgia y la reconstrucción del pasado y del presente (Bardestein, 2002: 358). Aunque existe la asociación de la comida con la esfera femenina (las recetas de Mamita Angélica y Mamita Lucía) y con el cuidado y protección de la función maternal, se pueden reconocer cambios de género, pues los hombres en la tercera generación empiezan a participar en una esfera cultural femenina. Mientras tanto, algunas mujeres, en la misma generación, la de las nietas, rechazan roles femeninos y participan en el consumo y disfrute de los platos y ya no en su preparación - un rol masculino. Es interesante que Mamita Lucía no considere a las recetas mismas como el aporte más importante del libro de cocina: "El consejo es lo que más me interesaría. Mis recetas no sé si les sirvan porque en la actualidad las chicas no cocinan".

Como señala Bardenstein (2002: 361-2), “uno podría creer que existe un proceso natural de mantener las tradiciones culinarias, pasando una receta y el conocimiento incorporado de preparar un plato de madre a hija, de una generación sucesiva a la siguiente". Sin embargo, no existen transmisiones fluidas o no interrumpidas, sino más bien rupturas normativas experimentadas como una parte normal de la vida (Ibíd.).

Entonces, la noción de que el conocimiento culinario se pasa de madre, a hija, a nieta, es una noción idealizada. La transmisión de conocimientos no es estable o no ambigua. A pesar de que Mamita Lucía no cifra sus esperanzas en la continuidad de la memoria culinaria porque percibe un desinterés en la tercera generación, es justamente una nieta la que pone las recetas y los recuerdos juntos.

Un cambio en la experiencia de vida de la nieta fue el detonante del interés por aprender las recetas de cocina. Cuenta la nieta:

"Cuando me casé le llamé a la Mamita Lucía. No sabia cómo se hace el locro y ella por teléfono me daba la receta. Cocinaba y me salía muy parecido el sabor. También después le preguntaba a mi suegra. Cuando me di cuenta ya tenía un libro de recetas, y recetas muy antiguas, algunas que son muy quiteñas: rosas de nieve, pristiños, empanadas de mejido hechas con la botella de Güitig helada. Tiene sus secretos de cocina" ${ }^{\prime 10}$.

Existe un presupuesto según el cual la comida es un canal directo a un mundo originario y que pertenece a la esfera femenina y maternal (Bardenstein, 2002: 359). Sin embargo, las configuraciones de los conocimientos culinarios familiares son más complejas. La nieta no aprendió el conocimiento de las recetas de la Mamita Lucía por intermedio de la madre, sino que buscó el conocimiento directamente de ella: un salto del aprendizaje entre la primera y la tercera generación. Adicionalmente, en las recetas de Mamita Lucía, la nieta incorpora

9 Entrevista con Mamita Lucía.

10 Entrevista a Camila, nieta de Mamita Lucía (Quito, agosto de 2004). 
los saberes culinarios de los hombres de la tercera generación-un primo y su pareja-. Adicionalmente, hace una incorporación a una tradición culinaria que se pensaría por línea materna exclusivamente, de las recetas de su suegra. Entonces, un libro de recetas que podría imaginarse circunscrito a los nexos de la abuela, la Mamita Lucía, en realidad está compuesto también por conocimientos que no corresponden a la esfera femenina y maternal, sino a la masculina y afín.

Como en otros libros de cocina y de memorias, en el libro de Mamita Lucía no existe una "autenticidad tradicional y una pertenencia no ambigua", sino que se producen tensiones que se pueden ver tanto en los cambios en la transmisión de conocimiento de la comida" (Ibid: 384) -cambio de roles tradicionales de género con respecto a la comida- como en cambios en la afiliación colectiva y las prácticas identificatorias -en las recetas de Mamita Lucía no sólo están las "propias" a la identidad familiar sino los aportes de otros-.

\section{El significado de las historias contadas por las abuelas}

Tanto Mamita Lucía, como mi abuelita Mariana nos han contado sus vidas y las historias familiares en especial del lado matrilineal, y también mucho de lo que sabemos de las historias por el lado paterno. Para esa generación de mujeres la vida familiar estructura las narrativas, y muchos de los episodios contados están organizados en torno al matrimonio. Sus narrativas también aluden a la forma en que se desarrollaron los negocios familiares. Para la generación de los abuelos, los "buenos" matrimonios y las vidas laborales "exitosas" son los logros de género fundamentales (Cfr. Piscitelli, 1996: 95).

En las historias de las dos abuelas, el matrimonio constituye un punto de inflexión de sus narrativas. Como toda política del recordar, existe un inter-juego de la memoria y el olvido. Antes del libro de recetas, poco sabía la familia de la vida pre-matrimonial de la Mamita Lucía.

"La Mamita Lucía escribió la parte de la historia (en las memorias) que no habíamos sabido. Casi no habla de su papá. Esa parte triste de la historia no habia contado".

"Lo que cuenta es más anécdotas de su vida, o de su abuelito, o de su mamá, pero de ella muy poco. Por eso empecé desde alli" 11 .

Comentábamos con Camila que existe una parte de la historia de Mamita Lucía en la que hay un vacío. Solo se puede atisbar el dolor sobre el cual el olvido realiza la cura ${ }^{12}$ : el sufrimiento por la muerte paterna, los cambios que la familia tuvo que enfrentar, la privación económica y las nuevas parejas de la madre.

En el caso de mi abuelita Mariana, al narrar su historia de vida hace un pequeño resumen de la misma al comienzo de su narrativa y da un salto del colegio al matrimonio:

"Yo estudié desde los primeros años en el Colegio La Providencia. Estudié la primaria y luego la secundaria y me gradué de contadora. Luego, con el pasar del tiempo me casé, y me casé con un señor cuencano y fui a vivir a Cuenca".

Durante ese "pasar del tiempo", mi abuela trabajó como contadora, por siete años. Más adelante en su historia de vida sí hace referencia a estos años de vida laboral. Sin embargo, su trabajo y trayectoria profesional no organizan su biografía. Reelabora este primer silencio más adelante en la entrevista:

11 Entrevista con Camila, la nieta de Mamita Lucía (Quito, agosto de 2004).

12 El silencio -y el olvido- es un derecho. Como dice Jelín, "los silencios en las narrativas personales son... fundamentales. A menudo no son olvidos, sino opciones personales como «un modo de gestión de la identidad» ligado al proceso de «recuperar la vergüenza»" (2002: 114). 
“... yo trabajaba, yo fui empleada de la Ritz, que era un centro comercial en que se atendía electrodomésticos, había sección papelería, discos, en ese tiempo habia los fonógrafos y las vitrolas de RCA Víctor, entonces yo tenía una vida sumamente agitada, y después que me casé fue una vida el otro extremo. Entonces fue terrible para mi porque tanto la ciudad [Cuenca] como la vida del hogar era muy monótona y entonces al comienzo me molestaba, me hacía sufrir porque yo fui una mujer muy activa y que siempre me gustó estar en movimiento y esa vida tan conventual no me agradaba".

Las escasas referencias a la vida pre-matrimonial en el caso de Mamita Lucía, y las omisiones de la vida laboral de la abuelita Mariana, nos muestran narrativas que se negocian con relación a cierto ideal familiar. Como en el caso de los álbumes familiares, las narrativas femeninas se enfrentan a un ideal familiar caracterizado por los valores de cohesión y solidaridad y por ser la fuente de relaciones satisfactorias y duraderas (Holland, 1991).

Las versiones de las historias familiares están en tensión con ese ideal. Quien narra,

“...conciente de la posibilidad siempre presente del escándalo, incluirá momentos significativos y miembros familiares que calcen y rigurosamente excluirán a otros. Los individuos difíciles, como esposos divorciados o hermanos que no se avienen, tienden a estar ausentes. La enfermedad, la inhabilidad, la discapacidad son raramente visibles. La ilegitimidad se esconde" (Ibíd: 7).

Las vidas de todos los miembros de la familia están hechas de las experiencias de la casa, pero también de la escuela, el trabajo, los intereses individuales, la acción política y las vinculaciones institucionales, cada ámbito con su propia red de amigos, compañeros y compromisos. Holland (1991) sostiene que otras redes y solidaridades no se hacen visibles en el álbum de familia convencional, porque la sobrevaloración de la familia devalúa otras vidas. En el caso de las mujeres de esta generación, no sólo existe una sobrevaloración de lo familiar en el ámbito de la representación y la narrativa, sino que sus vidas sí fueron transformadas de acuerdo al ideal del ámbito femenino del hogar. Hablar sobre un "buen matrimonio" y "una familia feliz" implica sacrificar ciertas memorias que ligan a las mujeres a lo público y lo laboral y a las memorias gratificantes de allí generadas, las cuales pondrían en entredicho la ideología familiar.

Las narrativas de las mujeres también se negocian con los ideales de feminidad. Piscitelli (1996) señala que las mujeres de todas las edades tienen como punto de referencia las oportunidades diferenciales de los hombres. Esta autora encontró que en las historias de vida nostálgicas de la generación de las abuelas la diferencia se acepta calmadamente y sólo en la siguiente generación se percibe amargura y frustración. Entre las abuelas de las dos familias en este trabajo, la negociación con el ideal femenino muestra que existen momentos de lucha que difieren de la calmada aceptación señalada por Piscitelli.

El énfasis en las historias sobre la bisabuela Luzita es la manera en la que en una familia se realiza la negociación con la feminidad. Una mujer profesional y trabajadora, características que normalmente se atribuyen a los caracteres masculinos de esta misma generación:

Mamacita todavía, no te digo que, mamacita murió en el año 63 y creo que unos cinco o seis años antes no más dejó de trabajar, sino que ella fue farmacéutica de la botica Sucre ${ }^{13}$.

Mamita Lucía señala un evento en el que rompió con la sumisión, justamente por no querer jugar el papel femenino de cocinar para invitados:

"Una vez me dijo [mi esposo] que tenía la posibilidad de comprar una quinta. "No me has de comprar porque yo no he de ir a pelar papas. Te irás solito". En esto de comprar una propiedad fuera de casa, la pobre mamá se quedaba ahí. En todo he sido sumisa, pero no en eso. "A mi a un hotel, o no voy". Las empleadas no quieren ir al campo. Yo me quedo en Quito".

13 Historia de vida de mi abuela (Quito, agosto de 2004). 
Algunas historias familiares contadas por las abuelas funcionan como "mitos familiares", es decir, a partir de ellas podemos acceder a un segundo nivel de significación, con un mensaje o significado ideológico más elaborado (Hall, 2000: 39). Alguna gente que he conocido relata episodios familiares en los que la familia había pasado por una tragedia económica y perdido su situación social previa. En ambas familias a las que aquí hacemos referencia también hemos escuchado este tipo de historias:

\begin{abstract}
"Estos días felices terminaron abruptamente. Muere mi papá de una manera repentina. Para nosotros fue la hecatombe, pues gozábamos de una situación privilegiada. Recuerdo que a papá le encantaba invitar a la hacienda a muchos amigos y parientes: mataban chanchos y festejaban por dias. En Quito hacía banquetes con champagna, nosotros creíamos que éramos riquísimas (de dinero). La oficina de mi papi tenía el siguiente cartel "De Banca e Importaciones". Mi papi lo habia perdido todo, cuando llega el abogado le recomendó a mami que renuncie a la herencia, porque habia más deudas que bienes. Mi mami así lo hizo y chao hacienda, casa y todo",14.
\end{abstract}

La familia de mi abuela también perdió todo lo que tenía por una garantía en un negocio. Ese hecho también significó un punto de inflexión en su vida ${ }^{15}$. Para ambas mujeres de esta generación, la "hecatombe" familiar marcó la época pre-matrimonial con fuertes limitaciones al estilo de vida que habían llevado y con cambios y reacomodos en la vida familiar ${ }^{16}$.

Para dar una explicación a estas narrativas es necesario ponerlas en relación con otras historias familiares. He mencionado ya que muchas de las historias que conocemos de los lados paternos de las familias, nos han sido contadas ya sea por nuestras abuelas o por nuestras madres más que por nuestros padres. Así, hemos escuchado las historias de los dos abuelos y aprendido la manera de "leer" esta parte de la historia familiar. En sus historias se enfatiza el crecimiento de sus comercios gracias a características masculinas - ambos abuelos grandes vendedores que gracias a su trabajo y carisma lograron que florezcan sus negocios:

\begin{abstract}
"Importaba mi marido máquinas de escribir, máquinas de cocer, molinos para granos, electrodomésticos, pianos; luego importó automóviles, importó también el gas. Fuimos unos de los primeros que trajimos el gas para las cocinas, importaba cocinas, en fin, él ha sido un hombre muy activo y el cielo nos bendijo porque nos faltaba tiempo para trabajar. Trabajábamos a toda hora, de noche y de día, se podría decir con exageración, pero nos iba muy bien. Y el Señorcito nos dio todo lo que anhelamos porque él nos dio lo que nunca soñamos" ${ }^{17}$.
\end{abstract}

"Ya empezaron a venir los carros. Manuel era el vendedor estrella. Se ganó la estatuilla al mejor vendedor de la Ford... Cuando ya era gerente, vino un día y me dijo. "Voy a renunciar". "¡Ay, no me hagas eso!". Le dije. "Voy a hacer una oficina chiquita para que ellos [los hijos] le hagan crecer". Se quedó en la Marín. Se quedó con cuatro carros usados que dejaban en Casabaca de segunda mano. Les cogía y les dejaba perfectos. Les vendía siquiera con el 50\%""18.

"La familia primero, las demás instituciones después, tiene un papel activo y directo en la socialización de las nuevas generaciones" (Jelín, 2002: 126). Estas historias parecen encontrar su punto de articulación en una masculinidad basada en el orgullo del trabajo (Leydersdorff et al., 1996: 11). Los abuelos de la familia han pasado desde temprano en la vida trabajando y a pulso han creado sus negocios: "Papavo era muy trabajador y visionario y todos siguen esa línea".

14 "Mamita Lucía: Memoria y Recuerdos".

15 Mi abuela no lo relata en la historia de vida, pero la historia ha llegado hasta mí a través de mi madre.

16 Como ya he mencionado, este tipo de historias se repiten en varias familias que he tenido la oportunidad de conocer. Por tanto habría que ver qué significado tienen. Aquí hago un intento de explicación, pero sería necesaria una investigación profunda para dar una respuesta al porqué de la recurrencia de este mito familiar.

17 Historia de vida de mi abuela (Quito, agosto de 2004).

18 Entrevista con Mamita Lucía (Quito, agosto de 2004). 
Bardenstein comenta que las memorias y libros de cocina del exilio palestino "parecen articular el mensaje más complicado de que la vida en el viejo mundo fue buena, luego se puso mala, y aunque ha sido posible hacer una vida decente o incluso muy buena aquí, siempre se hace con la conciencia de la ruptura, el cisma creado por el exilio" (2002: 365). En las historias de familia hay cierta similitud: perdimos una vida buena por la hecatombe familiar, pero la hemos recuperado gracias al trabajo. De esa manera, la ética del trabajo es uno de los mitos familiares que se puede rastrear en las historias: "Mi abuelo iba a trabajar con oxígeno", cuenta su nieta de Papavo. Este mito se complementa con el olfato y la sagacidad para los negocios y la astucia del buen vendedor. Al analizar las historias familiares, cabe preguntarse:

“¿Quién y qué se intenta transmitir y a quiénes? Para poder transmitir los sentidos del pasado hay al menos dos requisitos: el primero, que existan las bases para un proceso de identificación, para una ampliación inter-generacional del «nosotros». El segundo, dejar abierta la posibilidad de que quienes «reciben» le den su propio sentido, reinterpreten, resignifiquen -y no repitan o memoricen... no hay manera de obturar reinterpretaciones, resignificaciones, relecturas. Porque la «misma» historia, la «misma» verdad, cobra sentidos diversos en contextos diferentes. Y la sucesión de cohortes o generaciones implica, irremediablemente, la creación de nuevos contextos" (Jelín, 2002: 126).

El mensaje de estos mitos familiares abre entre las tres generaciones un "nosotros", aunque el mito de la ética del trabajo ha sido transformado por las siguientes generaciones. Las dos mujeres de la segunda generación, las madres, entraron a trabajar en los negocios familiares al terminar el colegio. Por tanto, las mujeres de esta generación han construido sus vidas ya no sólo en torno al hogar, sino también en relación con la vida laboral en los negocios familiares. Para su construcción identitaria es importante la idea de la "mujer trabajadora", aunque sus narrativas "continúan organizadas alrededor de la vida afectiva" (Piscitelli, 1996: 100).

Jelín (2002: 126) sostiene que se espera un cambio de significación de las historias familiares entre las generaciones, pues en la modernidad la socialización presupone sujetos reflexivos, con la capacidad de elegir y organizar sus vidas, y no existe una transmisión de patrones sociales de comportamientos explícitos. Esto se percibe ya en la segunda generación de mujeres de estas familias, quienes combinan trabajo y hogar.

En las terceras generaciones, las nietas realizan un trabajo de identidad y memoria ligado a un sentido de permanencia, de mismidad a lo largo del tiempo y del espacio (Ibíd.: 24). Las nietas toman no sólo los elementos de la "masculinidad basada en la ética del trabajo", sino que dan importancia a otros aspectos de las historias de las familias. Se ve entonces el cambio del significado entre las generaciones, al analizar las continuidades y las rupturas en las tradiciones familiares: "las historias no son meros repositorios de estereotipos de género. Sino que su uso presente en la vida de la generación más joven es importante en la construcción de nuevas concepciones de los principios de diferenciación de género" (Piscitelli, 1996: 91).

La generación de las nietas también negocia su proyecto de feminidad y para ello hace uso de las historias familiares. Las nietas vuelven su vista a la primera generación y encuentran que las mujeres de la familia han hecho otras cosas que sobrepasan el ámbito tradicionalmente femenino y privado del hogar. Mi bisabuela, mi abuela y mi madre tienen cosas que contarme, que van más allá de los estereotipos de pasividad y sumisión. Me hablan de mujeres activas, trabajadoras y que obtienen gratificaciones del ámbito profesional y laboral. De igual manera, la nieta de Mamita Lucía ve en ella a

“...una persona muy activa. Maneja, viaja, va de compras, hace ropa, juega baraja". Ante la pasividad, la actividad. Hacer cosas diferentes en la vida, una posibilidad de salir de las representaciones de las contribuciones de las mujeres "en términos de sacrificio, un rol femenino tradicional que sólo refuerza los estereotipos de género" (Gillis, 1994: 12). 
Aquí, las mujeres de las tres generaciones impugnan los valores que supuestamente caracterizan a las mujeres latinoamericanas, y muestran los límites de generalizaciones basadas en el concepto de marianismo (Stevens, 1974).

Además de transmitir un mensaje en clave de género, las memorias familiares sirven para situar a las familias en el contexto social más amplio. Las memorias familiares son, en gran medida, proyectos de clase. Esto se ve con claridad en las referencias a los mitos del orgullo del trabajo y la superación de hecatombes familiares. En un contexto diferente, el de las familias chicanas en los Estados Unidos, las historias familiares funcionan como un tipo de capital cultural para la movilidad educativa. Dichas historias hacen referencia a familias que eran pudientes en México, que habían logrado un alto nivel educativo, o que habían perdido sus fortunas (Bettie, 2003: 153). Las historias familiares sirven en dicho contexto para transmitir una disposición de clase hacia la educación formal y el éxito de estudiantes de clase trabajadora. En las historias familiares que aquí analizo, también existe una socialización y una disposición hacia la movilidad social, en las historias de hecatombe y posterior éxito, que crea una "una percepción positiva de uno y de su familia y suscita en los hijos una sensación de esperanza y merecimiento" (Ibíd.: 154).

Las historias de las mujeres nos proveen de un pasado que "ofrece una pantalla en la cual se puede proyectar el deseo de unidad y continuidad, esto es, de identidad (Gillis, 1994: 9). Las lecturas que cada generación hace se ubican en marcos sociales o matrices grupales que les dan sentido (Jelín, 2002: 21). Desde estos contextos, las nietas hacemos una reactivación del pasado y creamos "nuestros propios" recuerdos, en un diálogo con los cambios en la ideología familiar, en las relaciones entre géneros y en los proyectos de feminidad.

\section{Nuestro tributo: la memoria}

Parte de la socialización femenina es aprender a cuidar, conservar y nutrir nuestras historias familiares: atesoramos nuestras memorias. Las mujeres continúan jugando el rol de los ejes alrededor de los cuales se tejen los afectos familiares. Las mujeres "están pendientes". Toman a su cargo "la compulsión actual de recordar los cumpleaños y aniversarios de la familia" (Gillis, 1994: 15). Decía un amnésico que "«cuando no tienes memoria, no tienes sentimientos». La pérdida de memoria destruye la personalidad y priva a la vida de significado" (Lowenthal, 1985: 197) y las mujeres de la familia tejen significados y ofrecen a los miembros de la familia narrativas de identidad familiar y de género.

Las mujeres y minorías frecuentemente sirven como símbolos de un pasado "perdido" percibido nostálgicamente y construido románticamente, pero fácilmente se olvidan sus vidas reales (Gillis, 1994: 10). La memoria de las mujeres de la familia trabaja en contra de este olvido social de las historias femeninas. Mi amiga Camila sabe de Mamita Lucía y Mamita Angélica, como yo de la abuelita Mariana y la abuelita Luz María. Hacer el libro de recetas, le pareció a Camila un lindo tributo. Les hacemos un tributo a nuestras bisabuelas, abuelas y madres cuando tenemos interés en lo que nos pueden contar. Y el encantamiento con el cual solemos escuchar sus historias ${ }^{19}$ muestra la manera en la que hemos aprendido a relacionarnos con nuestras memorias: el afecto. Las líneas de transmisión de memorias familiares están cargadas de emoción. Conjuramos el olvido de las historias de las mujeres en los lazos de afecto y memoria matrilineales.

Las mujeres de la familia hacen uso de las historias familiares para tratar sus construcciones de género. Sus narrativas se negocian con las ideologías de feminidad, del ideal familiar y de la vida pública del trabajo y la profesión. "Las mujeres jóvenes tratan de explicar sus prácticas

19 Sobre todo entre la primera y tercera generación. A veces la relación entre segunda y tercera generación no posee este encantamiento. Mi madre señala que mi abuela y su hermana estaban cansadas de escuchar las "mismas historias", mientras a mi madre y sus hermanos les fascinaba oír al Tocito y al abuelito (mi tío bisabuelo y mi bisabuelo). 
innovadoras haciendo un diferente uso de las tradiciones familiares... que tienen que ver con una construcción de género" (Piscitelli, 1996: 102). Es por ello que en cada versión de las historias familiares se pueden percibir continuidades y rupturas, pues en los elementos que se destacan o se omiten se rastrean los contextos y marcos sociales diferenciados con los cuales interactúan y negocian las distintas generaciones.

Aunque no he analizado aquí estos aspectos, también existen narrativas que dan cuenta de las historias de ciudades como Ibarra, Quito o Cuenca y de la construcción de la "quiteñidad" frente a la gente de provincia y sus implicaciones con relación a jerarquías raciales. Todavía hay mucho más que decir sobre las tradiciones familiares: sobre la conformación de gustos, no sólo culinarios, que se transmiten a través de las familias y que les otorgan continuidad. Espero que este trabajo logre plasmar en algo la riqueza de las historias familiares y haga justicia a los aportes hechos por las diferentes mujeres que intervinieron en realizarlo. 


\section{Bibliografía}

Alcoff, L. 1991, "The Problem of Speaking of Others", en: Cultural Critique, No. 20, (Winter 1991-1992), pp. 5-32.

Bardenstein, Carol. 2002, "The Gender of Nostalgia. Transmissions Interrupted: reconfiguring Food, Memory, and Gender in the Cookbook-Memoirs of Middle Eastern Exiles”, en: Hirsch M. y V. Smith (Eds.) Signs, Vol. 28. $\mathrm{N}^{\circ} 1$, Special Issue.

Bettie, J. 2003, Women without Class. Gender, Race, and Identity, The University of California Press, Berkeley y Los Angeles.

Counihan, Carole. 2012, “Gendering Food”, en: Pilcher, Jeffrey (Ed.) The Oxford Handbook of Food History, Oxford: Oxford University Press, pp. 99-116.

Jelín, Elizabeth. 2002, Los Trabajos de la Memoria. Madrid, Siglo XXI Editores.

Gillis, John. 1994, "Memory and Identity. The History of a Relationship", en Gillis, John (Ed.) Conmemorations: the Politics of National Identity, Princeton University Press, Princenton.

Holland, Patricia. 1991, "Introduction. History, Memory and the Family Album”, en: Spence Jo y Patricia Holland (Eds.), Family Snaps. The Meanings of Domestic Photography, Virago Press, London, pp. 1-14.

Leydersdorff, Selma et al. 1996, "Introduction", en: International Yearbook of Oral History and Life Stories, Vol. IV. Gender and Memory, Oxford University Press.

Lowenthal, David. 1985, The past is a foreign country, Cambridge University Press.

Lugones, M. y E. Spelman. 1986, "Have we got a theory for you! Feminist theory, cultural imperialism and the demand for 'the woman's voice", en: Pearsall, M. (Ed.) Women and values: Readings in recent feminist philosophy, Wadsworth Publishing Company, Belmont, CA.

Pilcher, Jeffrey. 2012, “Cultural Histories of Food”, en: Pilcher, Jeffrey (Ed.) The Oxford Handbook of Food History, Oxford University Press, Oxford, pp. 41-61.

Piscitelli, Adriana. 1996, "Love and Ambition. Gender, Memory, and Stories from Brazilian Coffee Plantation Families", en: Leydersdorff, Selma, et al. International Yearbook of Oral History and Life Stories, Vol. IV. Gender and Memory, Oxford University Press.

Siebert, Renate. 1996, "Women and the Mafia. The power of Silence and Memory", en: Leydersdorff, Selma et al., International Yearbook of Oral History and Life Stories, Vol. IV, Gender and Memory, Oxford University Press.

Stevens, Evelyn. 1974, "El marianismo: la otra cara del machismo en América Latina”, en: Diálogos: Artes, Letras, Ciencias Humanas, Vol. 10, No. 1 (55) (enero-febrero 1974), pp. 17-24. 